\title{
The Significance of Early Repolarization and Incomplete Right Bundle Block in Athletes
}

\author{
Samir Rafla, MD, PhD ${ }^{*}$ (D) Gamal Abd Elnasser Younes Mahmoud, PhD², Ahmed Abdel Salam Nassar, \\ $M B$ ChB, $M S^{3}$ and Amr Kamal, MD, PhD ${ }^{3}$ (D)
}

${ }^{1}$ Emeritus Professor of Cardiology, Alexandria University, Egypt

${ }^{2}$ Assistant Professor, Department of Biological and Sports Health Sciences, Faculty of Sport Education. Alexandria University, Egypt

${ }^{3}$ Cardiology Department, Faculty of Medicine, University of Alexandria, Egypt

*Corresponding author: Samir Rafla, MD, Ph.D, FACC, FHRS, EFESC, Member EHRA, Emeritus Professor of Cardiology, Alexandria University, Egypt, E-mail: smrafla@yahoo.com, Tel: 01001495577

\begin{abstract}
Background: Sudden death in athletes is a major concern; the predictors remain to be settled. The significance of early repolarization is the subject of this work.

Methods: The study included hundred persons engaged in competitive sports for duration not less than 6 months; with training at least 3 days per week and at least two hours per day. All were males. Full history especially questioning for syncope, tachycardias or chest pain was obtained as well as family history of sudden death or coronary disease. ECG was done for all plus echo Doppler in some cases. Early repolarization was accepted present if $\mathrm{J}$ point is elevated more than one $\mathrm{mm}$ in LII, III, aVF or in chest leads, with or without raised $\mathrm{ST}>1 \mathrm{~mm}$. RV conduction disturbance was considered present if there is Rsr' or bifid R. 54 played isotonic sport while 46 were on isometric sport. Types of sports: 46 isometric (static) (body builders). Isotonic (dynamic) 54 (Bicycling 6, Football 15, Tennis 3, Basketball 16, Volleyball 8, Swimming 4, Boxing 2).
\end{abstract}

Results: Early repolarization was found in 9 and Rsr' were present in 14 subjects, (5 had both). None was diagnosed as Brugada or RV dysplasia. Echo was done in 15 who showed ECG increased voltage, increase in LV size was found in 5 (Diastolic diameter up to $61 \mathrm{~mm}$ ). 10 persons were re-examined after months, no abnormal events were found. Follow up by telephone was up to two years. No one reported tachyarrhythmia or syncope neither before recruitment in the study (retrospective) or after follow-up (prospective).

Conclusion: Early repolarization and RV conduction disturbance in athletes apparently did not prove to be hazardous. Further studies are needed.

\section{Keywords}

Sudden cardiac death, Early repolarization syndrome, Incomplete right bundle branch block, Athletes, Routine ECG, Brugada syndrome

\section{Abbreviations \\ ERS: Early Repolarization Syndrome; LVH: Left Ventricular Hypertrophy}

\section{Introduction}

Early Repolarization (ER), also recognized as "J-waves" or "J-point elevation"' is an electrocardiographic abnormality consistent with elevation of the junction between the end of the QRS complex and the beginning of the ST segment in 2 contiguous leads.

Early Repolarization Syndrome (ERS), demonstrated as J-point elevation on an electrocardiograph, was formerly thought to be a benign entity. Recent studies have demonstrated that it can be linked to a higher risk of ventricular arrhythmias and sudden cardiac death [1-8]. The prevalence of ERS varies between 3\% and $24 \%$, depending on age, sex and J-point elevation $(0.05 \mathrm{mV}$ vs. $0.1 \mathrm{mV}$ ) being the main determinants. ERS patients are sporadic and they are at a higher risk of having recurrent cardiac events. Isoproterenol are the suggested therapies in this set of patients. On the other hand, asymptomatic patients with ERS are common and have a better prognosis [4].

Citation: Rafla S, Younes, G.A.E, Nassar A, Kamal A (2020) The Significance of Early Repolarization and Incomplete Right Bundle Block in Athletes. Int J Sports Exerc Med 6:168. doi.org/10.23937/24695718/1510168

Accepted: June 10, 2020; Published: June 12, 2020

Copyright: (C) 2020 Rafla S, et al. This is an open-access article distributed under the terms of the Creative Commons Attribution License, which permits unrestricted use, distribution, and reproduction in any medium, provided the original author and source are credited. 
Early Repolarization Syndrome (ERS)" was regarded as a "normal variant", or a "benign early repolarization" until 2000 [5]. However, numerous more recent reports have suggested a relationship between ER and an increased risk of death from cardiac arrhythmias.

\section{Methods}

\section{Subjects}

The study included hundred subjects engaged in competitive sports for duration not less than 6 months and with training at least 3 days per week and at least one hour per day. Inclusion criteria: Any type of sport, football or basketball, swimming, weight lifting or running. They divided into two broad types: dynamic (isotonic) and static (isometric). Age range 18 to 45 years. Only males were studied.

\section{Selection bias}

We went to sports clubs and gym centers, we recorded ECGs to players at end of matches or the couch brought the players available. We did not exclude or select specific players so there was no bias.

\section{Female players}

In a conservative country we cannot go to clubs and make ECGs to females. No chance to bring with me female nurse to do the ECG under cover.

\section{Tools of data collection}

The subjects in the study were subjected to: History taking: Full history especially questioning for syncope or chest pain. Family history of sudden death or coronary disease. Clinical examination: Examination for BP, any cardiac murmurs or arrhythmia. Weight and height to calculate body mass index. Investigations: ECG was done for all and examined for rate, rhythm, voltage, ST, QT and recording of any abnormality. Voltage means length of $R$ and $S$ in limb and chest leads. Left ventricular hypertrophy was considered according to Sokolow-lyon criteria. The ECG apparatuses used were Fukoda Denchi and Schiller. Both calculate QTC.

A standard 12-lead ECG was performed on competitive athletes who are apparently normal in the supine position during quiet respiration and recorded at $25 \mathrm{~mm}$ per second. Echocardiography was done for cases that are suspicious.

Echo measured LV size (diameters, mass index), Ejection fraction, diastolic function, any valvular lesions, pulmonary hypertension and right ventricular measurements. The echo apparatus was Esaote my lab Gold 30. It calculates LV mass from wall thickness and cavity diameters. Three recordings were done and the sum is considered.

\section{Statistical analysis of the data}

Data were analyzed using software (SPSS 23). Descriptive data was expressed in frequency and percent and was analyzed using Chi-square test also exact tests such Fisher exact and Monte Carlo was applied to com-

Table 1: Relation between type sports with ECG changes.

\begin{tabular}{|c|c|c|c|c|c|c|c|c|}
\hline \multirow{3}{*}{ ECG changes } & \multirow{2}{*}{\multicolumn{2}{|c|}{$\begin{array}{c}\text { Total } \\
(n=100)\end{array}$}} & \multicolumn{4}{|c|}{ Type sport } & \multirow{3}{*}{$x^{2}$} & \multirow{3}{*}{$\mathbf{p}$} \\
\hline & & & \multicolumn{2}{|c|}{$\begin{array}{c}\text { Isotonic } \\
(n=54)\end{array}$} & \multicolumn{2}{|c|}{$\begin{array}{l}\text { Isometric } \\
(n=46)\end{array}$} & & \\
\hline & No. & $\%$ & No. & $\%$ & No. & $\%$ & & \\
\hline \multicolumn{9}{|l|}{ LVH } \\
\hline Absent & 82 & 82.0 & 41 & 75.9 & 41 & 89.1 & \multirow{2}{*}{2.934} & \multirow{2}{*}{0.087} \\
\hline Present & 18 & 18.0 & 13 & 24.1 & 5 & 10.9 & & \\
\hline \multicolumn{9}{|l|}{ Early repolarization } \\
\hline Absent & 95 & 95.0 & 49 & 90.7 & 46 & 100.0 & \multirow{2}{*}{4.483} & \multirow{2}{*}{0.01} \\
\hline Present & 9 & 5.0 & 9 & 18 & 0 & 0.0 & & \\
\hline \multicolumn{9}{|l|}{$\mathrm{HR}<60$} \\
\hline Absent & 94 & 94.0 & 48 & 88.9 & 46 & 100.0 & \multirow{2}{*}{$5.437^{*}$} & \multirow{2}{*}{$\mathrm{FE}_{\mathrm{p}}=0.030^{*}$} \\
\hline Present & 6 & 6.0 & 6 & 11.1 & 0 & 0.0 & & \\
\hline \multicolumn{9}{|l|}{ Rsr' } \\
\hline Absent & 86 & 86.0 & 43 & 79.6 & 43 & 93.5 & \multirow{2}{*}{$3.957^{*}$} & \multirow{2}{*}{$0.047^{\circ}$} \\
\hline Present & 14 & 14.0 & 11 & 20.4 & 3 & 6.5 & & \\
\hline \multicolumn{9}{|l|}{ Inverted T } \\
\hline Absent & 97 & 97.0 & 52 & 96.3 & 45 & 97.8 & \multirow{2}{*}{0.200} & \multirow{2}{*}{$\mathrm{FE}_{\mathrm{p}}=1.000$} \\
\hline Present & 3 & 3.0 & 2 & 3.7 & 1 & 2.0 & & \\
\hline \multicolumn{9}{|l|}{ Sinus arrhythmia } \\
\hline Absent & 94 & 94.0 & 50 & 92.6 & 44 & 95.7 & \multirow{2}{*}{0.412} & \multirow{2}{*}{${ }^{\mathrm{FE}} \mathrm{p}=0.684$} \\
\hline Present & 6 & 6.0 & 7 & 7.4 & 2 & 4.3 & & \\
\hline
\end{tabular}

$\chi^{2}$ : Chi square test. FE: Fisher Exact for Chi square test 
pare different groups. P value was assumed to be significant at (0.05) with confidence interval set at 95\% (Table $1)$.

\section{Results}

During the period from $1 / 1 / 2015$ to $1 / 10 / 2016,100$ athletes were screened by ECG. 54 played isotonic sport while 46 were on isometric sport. According to the past medical history: 11 (11\%) patients were hypertensive, 9 (9\%) were symptomatic (history of atypical chest pain or undue palpitations or occasional dizziness but no history of syncope), 1 (1\%) was with positive family history for

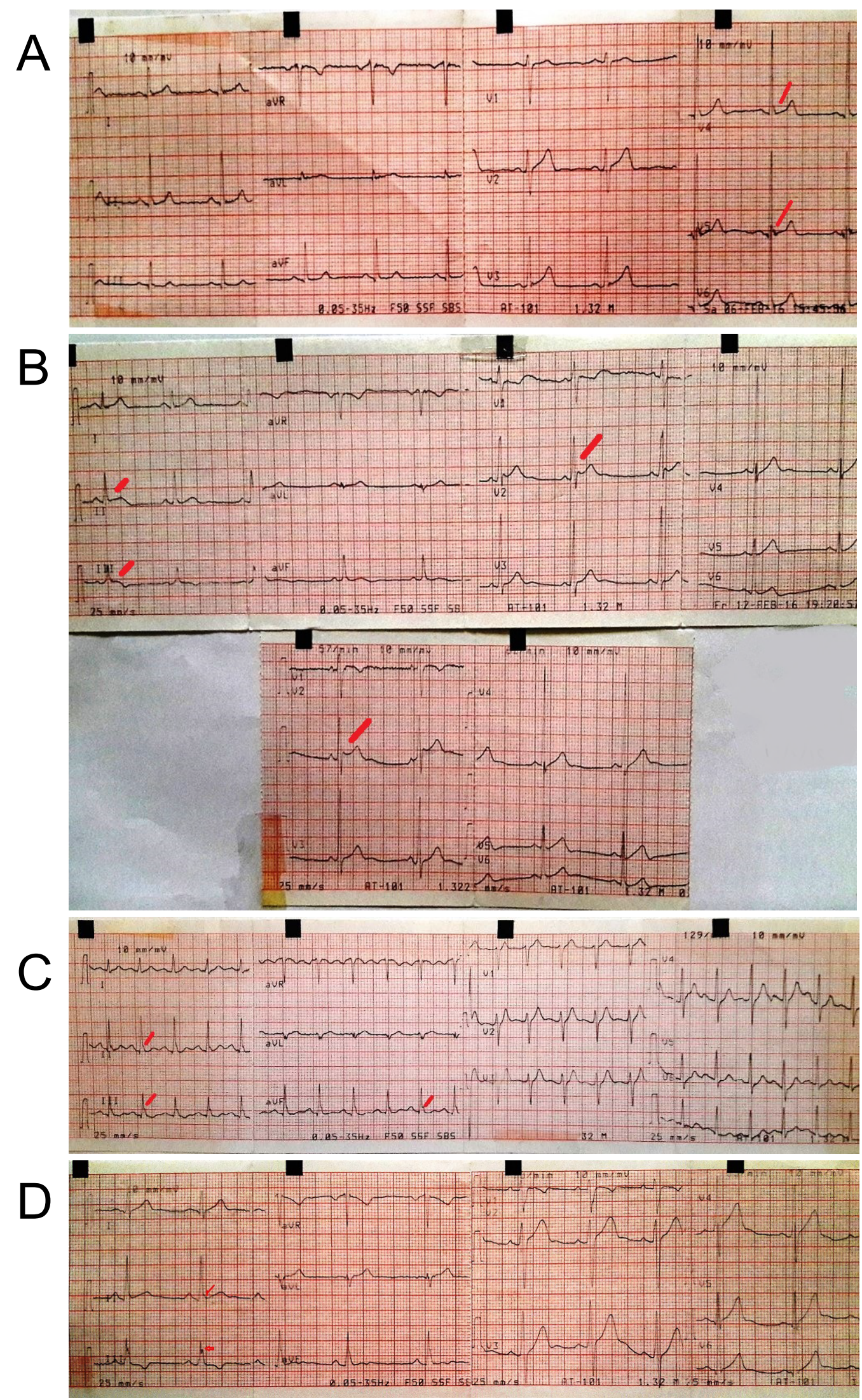

Figure 1: (a-d) Early repolarization syndrome. 


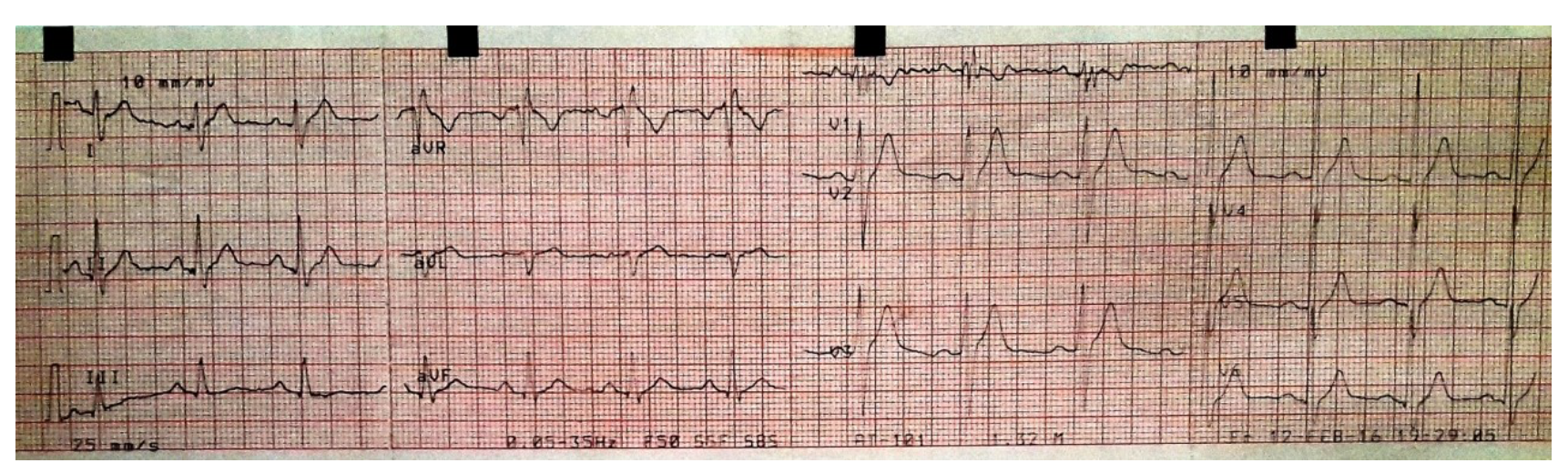

Figure 2: Bifid R.

cardiac diseases and seven (7\%) were smokers (Figure 1a, Figure 1b, Figure 1c, Figure 1d, Figure 2).

\section{Types of sports}

46 isometric (static) (body builders). Isotonic (dynamic) 54 (Bicycling 6, Football 15, Tennis 3, Basketball 16, Volleyball 8, Swimming 4, Boxing 2). Echo was done in 15, increase in LV size was found in 5 (Diastolic diameter up to $61 \mathrm{~mm}$ ). 18 athletes showed LVH by ECG (by Sokolow-Lyon Criteria). Correlation between the 18 athletes with ECG LVH and echocardiography: Only 5 of the 18 showed increased diameters by echo but within accepted athletic heart criteria. Two of body builders confessed of taking doping drugs (male hormones) but no clinical abnormal signs were detected. No long QT was found. ECG changes were more in isometric (static) athletes (body builders).

The significance of finding more ECG changes in isometric (static) athletes is not clear but clinically did not show any effect. Two of body builders confessed of taking doping drugs (male hormones) but no clinical abnormal signs were detected. No long QT was found.

\section{Follow up}

Athletes were followed by telephone for one year. In 5 the telephone number was wrong so no data and in 6 telephone answer so no data. The remaining 89 athletes reported no undue attacks of tachycardia or symptoms as syncope or chest pain. Only two reported complaints and were asked to come to my clinic for free reexamination by ECG and echo. No abnormal findings were found.

No Holter monitoring was applied, no exercise ECG was done.

\section{Correlation between the 18 athletes with ECG LVH and echocardiography}

All 18 athletes with ECG increased voltage ( $R$ plus $S$ in chest leads $>36 \mathrm{~mm}$ ) were called to our clinic and echocardiography was done. It was normal in all except 5 who showed LV diameter $>57 \mathrm{~mm}$ but less than 61 $\mathrm{mm}$ denoting athletic heart not pathological. Ejection fraction and diastolic function were normal.
We did not tell the athletes or their coach that there is something in the ECG to avoid undue anxiety or bad consequences.

\section{Discussion}

Sudden death in athletes is a major concern; the predictors and value of prior investigations remain to be settled. The work aims to study electrocardiograms (ECG) in competitive athletes to define incidence of abnormalities and any relevant associations. During the period from $1 / 1 / 2015$ to $1 / 10 / 2016,100$ athletes were screened by ECG, 54 played isotonic sport while 46 were on isometric sport in Alexandria. The mean age of athletes was 23.3 years, and the mean BMI of athletes was 24.19. We observed that (11\%) athletes were hypertensive, $(9 \%)$ were with cardiac symptom, $(1 \%)$ was with positive family history for cardiac diseases and (7\%) were smokers. 12 leads ECG was done to all athletes: LVH by voltage criteria were found in $18 \%$ of athletes, Early repolarization in 5\%, bradycardia in $6 \%$, RBBB in $14 \%$, Inverted $\mathrm{T}$ in $3 \%$ and Sinus arrhythmia in $6 \%$ and we observed that $43 \%$ of all athletes were with at least one ECG changes, while it was up to $60 \%$ of athletes as described by Leite, et al.) [9-11].

The most commonly used voltage criterion for LVH is the Sokolow-Lyon index. However, ECG QRS voltage may not be a reliable predictor of LVH. In athletes, intensive conditioning is also associated with morphological cardiac changes of increased cavity dimensions and wall thickness that are reflected on the ECG. These changes constitute physiological LVH in trained athletes and usually manifests as an isolated increase in QRS amplitude, LVH are prevalent and present in up to $18 \%$ of athletes. Drezner JA, et al. Drezner, Ackerman et al. $[12,13]$ reported that present in up to $45 \%$ of athletes. A high prevalence of ECGs that fulfil Sokolow-Lyon voltage criteria for LV hypertrophy has been consistently reported in trained athletes assessed the prevalence and type of ECG abnormalities in 1005 elite Italian athletes, 75\% male who participated in 38 sporting disciplines [1].

Early repolarization has traditionally been regarded as an idiopathic and benign ECG phenomenon, with a clear male preponderance. The early repolarization ECG 
pattern is the rule rather than the exception among highly trained athletes. The early repolarization ECG shows elevation of the QRS-ST junction (J-point) of at least 0.1 $\mathrm{mV}$ from baseline, associated with notching or slurring of the terminal QRS complex which may vary in location, morphology, and degree. These changes often are localized in precordial leads, with the greatest ST-segment elevation in mid-to-lateral leads (V3-V4), but maximal ST-segment displacement may also be seen in lateral leads (V5, V6, I, and aVL), inferiorly (II, III, and aVF), or anteriorly (V2-V3).

Early repolarisation is reported in up to $35-91 \%$ of trained athletes and is more prevalent in young males and black by Drezner JA, et al. [12,13] $50 \%$ to $80 \%$ of all highly-trained athletes present have early repolarization reported and it was observed in $50-80 \%$ of resting ECGs by Biffi, Alessandro [1], and it was less than $10 \%$ of the 15,000 participants reported by Sinner, Moritz F, while it was only in $5 \%$ of the athletes in our study.

The normal heart beat is initiated by the sinus node which is located high in the right atrium near the junction of the superior vena cava and the right atrial appendage. To be classified as sinus rhythm, three criteria must be met: (1) There must be a $P$ wave before every QRS complex, (2) There must be a QRS complex after every $P$ wave and (3) The $P$ wave must have a normal axis in the frontal plane $\left(0-90^{\circ} \mathrm{s}\right)$. Assuming an intact sinus node, the heart rate is set by the balance between the sympathetic and parasympathetic nervous systems. In healthy adults, sinus rhythm $<60$ beats/min is considered as 'sinus bradycardia'. In well-trained athletes, resting sinus bradycardia is a common finding due to increased vagal tone, it was only in $6 \%$ of the athletes in our study. IRBBB is defined by a QRS duration $<120$ ms with an RBBB pattern: Terminal $R$ wave in lead $V 1$ ( $r R^{\prime}$ ) and wide terminal $S$ wave in leads I and V6. IRBBB is observed in up to $40 \%$ of highly trained athletes according to Drezner JA, Fischbach $\mathrm{P}$, Froelicher V, et al. [12], and incomplete Right Bundle Branch Block (RBBB) was in $33 \%$ of the athletes in van Dijk, Gaby Pons, $35 \%$ to $50 \%$ of athletes have an incomplete right bundle branch block according to Scharhag, Jürgen and The prevalence of incomplete right bundle branch block has been estimated to range from 35 to $50 \%$ in athletes as written by Biffi, Alessandro (Biffi, Delise et al.) [1], while it was $14 \%$ of the athletes in our study. T-wave inversion is defined as $>1 \mathrm{~mm}$ in depth in two or more leads V2-V6, II and aVF, or I and aVL (excludes III, aVR and V1).

T-wave inversion in inferior (II, III, aVF) and/or lateral (I, aVL, V5-V6) leads must raise the suspicion of ischaemic heart disease, cardiomyopathy, aortic valve disease, systemic hypertension, and LV non-compaction. T-wave inversion listed as Abnormal and uncommon ECG findings in athletes and reported in $2 \%$ of athletes by Drezner, Fischbach et al. 2013) [13-16], and identified in only $0.1 \%$ to $0.2 \%$ of athletes according to D'Silva and Sharma [17] , while it was only $1.4 \%$ as described by Biffi, et al. [1], and it was in $5 \%$ of the athletes in our study.

The heart rate usually increases slightly during inspiration and decreases slightly during expiration. This response called sinus arrhythmia can be quite exaggerated in children and in well-trained athletes resulting in an irregular heart rhythm which originates from the sinus node. It has been estimated that up to $55 \%$ of well-trained athletes have sinus arrhythmia reported by (Drezner JA, Ackerman) [11]; Drezner JA, Fischbach $P,[12]$. While we found sinus arrhythmia in $6 \%$ of the athletes. At least we didn't find any of uncommon ECGs that was reported by Drezner JA, et al. [11]. Echocardiography was done in 15 players, increase in LV size was found in 5 players only. Follow up by telephone questionnaire was done for all, 5 persons were re-examined after months, no abnormal events were found.

\section{Clinical Manifestations of ERS}

The clinical presentation of patients with ERS can be subdivided into two main groups. The first includes those that manifest recognized symptoms of ERS, i.e., high risk patients with syncope and survivors of cardiac arrest. A study by Abe, et al. [17] demonstrated that the ER was noticed in $18.5 \%$ in patients with syncope compared to $2 \%$ in healthy controls, this equates to almost 10 - fold increase risk of syncope in patients with ERS.

The second and the most common group are asymptomatic patients who are incidentally noted to have an ER pattern on their ECG. Overall, this group is less likely to have adverse cardiac events, and the challenge here lies in distinguishing those with risk of sudden cardiac death from those that are likely to run a benign course of the condition [11-21].

\section{ECG Diagnosis of ERS}

The electrocardiographic hallmark of ERS is elevation (> $1 \mathrm{~mm}$ above baseline) of the QRS-ST junction manifested as either QRS slurring or notching, ST-segment elevation with upper concavity, and prominent T-waves in two or more contiguous inferior and/or lateral leads in a patient resuscitated from otherwise unexplained ventricular arrhythmia [15]. Recent studies omitted ST segment elevation from the definition of ERS, and state that the J point changes described above is sufficient to diagnose ERS [9]. The inclusion or exclusion of right precordial leads is also an area for debate [22-29].

\section{Conclusions}

Early repolarization and incomplete right bundle block were apparently not associated with proved hazard in this study. In spite the study is small or limited; we think it adds to the literature of this subject. It ameliorates the bad reputation of early repolarization. All patients with ER should continue to have follow up and risk assessment. 


\section{References}

1. Biffi A, Delise P, Zeppilli P, Giada F, Pelliccia A, et al. (2013) Italian cardiological guidelines for sports eligibility in athletes with heart disease: part 1. J Cardiovasc Med (Hagerstown) 14: 477-499.

2. Brugada J, Brugada R, Brugada P (1998)Right bundle-branch block and ST-segment elevation in leads V1 through V3: A marker for sudden death in patients without demonstrable structural heart disease. Circulation 97: 457-460.

3. Zipes DP, Wellens HJ (1998) Sudden cardiac death. Circulation 98: 2334-2351.

4. Haïssaguerre M, Derval N, Sacher F, Jesel L, Deisenhofer I, et al. (2008) Sudden cardiac arrest associated with early repolarization. N Engl J Med 358: 2016-2023.

5. Klatsky AL, Oehm R, Cooper RA, Udaltsova N, Armstrong MA (2003) The early repolarization normal variant electrocardiogram: Correlates and consequences. Am J Med 115: 171-177.

6. Gussak I, Antzelevitch C (2000) Early repolarization syndrome: Clinical characteristics and possible cellular and ionic mechanisms. J Electrocardiol 33: 299-309.

7. Tikkanen JT, Anttonen O, Junttila MJ, Aro AL, Kerola T, et al. (2009) Long-term outcome associated with early repolarization on electrocardiography. N Engl J Med 361: 25292537.

8. Rosso R, Kogan E, Belhassen B, Rozovski U, Scheinman MM, et al. (2008) J-point elevation in survivors of primary ventricular fibrillation and matched control subjects: Incidence and clinical significance. J Am Coll Cardiol 52: 12311238.

9. Sinner MF, Reinhard W, Müller M, Beckmann BM, Martens E, et al. (2010) Association of early repolarization pattern on ECG with risk of cardiac and all-cause mortality: A population-based prospective cohort study (MONICA/KORA) PLoS Med 7: e1000314

10. Corrado D, Biffi A, Basso C, Pelliccia A, Thiene G (2009) 12-lead ECG in the athlete: Physiological versus pathological abnormalities. Br J Sports Med 43: 669-676.

11. Leite MS, Freitas J, Campelo M, Maciel MJ (2016) Electrocardiographic evaluation in athletes: 'Normal' changes in the athlete's heart and benefits and disadvantages of screening. Rev Port Cardiol 35: 169-177.

12. Drezner AJ, Ackerman MJ, Anderson J, Ashley E, Asplund CA, et al. (2013) Electrocardiographic interpretation in athletes: The 'Seattle Criteria'. Br J Sports Med 3: 122-124.

13. Drezner JA, Fischbach P, Froelicher V, Marek J, Pelliccia A, et al. (2013) Normal electrocardiographic findings: Recognising physiological adaptations in athletes. $\mathrm{Br} \mathrm{J}$ Sports Med 47: 125-136.

14. Haruta D, Matsuo K, Tsuneto A, Ichimura S, Hida A, et al. (2011) Incidence and prognostic value of early repolarization pattern in the 12-lead electrocardiogram. Circulation 123: 2931-2937.

15. Olson KA, Viera AJ, Soliman EZ, Crow RS, Rosamond WD
(2011) Long-term prognosis associated with J-point elevation in a large middle-aged biracial cohort: the ARIC study. Eur Heart J 32: 3098-3106.

16. Abe A, Ikeda T, Tsukada T, Ishiguro H, Miwa Y, et al. (2010) Circadian variation of late potentials in idiopathic ventricular fibrillation associated with J waves: Insights into alternative pathophysiology and risk stratification. Heart Rhythm 7: 675-682.

17. D'Silva A, D'Silva A, Sharma S (2014) Exercise, the athlete's heart, and sudden cardiac death. The Physician and Sports medicine 42: 100-113.

18. Nam GB, Ko KH, Kim J, Park KM, Rhee KS, et al. (2010) Mode of onset of ventricular fibrillation in patients with early repolarization pattern vs. Brugada syndrome. Eur Heart J 31: 330-339.

19. Miyazaki S, Shah AJ, Haïssaguerre M (2010) Early repolarization syndrome - a new electrical disorder associated with sudden cardiac death. Circ J 74: 2039-2044.

20. Serra-Grima R, Doñate M, Álvarez-García J, Barradas-Pires A, Ferrero A, et al. (2015) Long-term follow-up of early repolarization pattern in elite athletes. Am J Med 128: 192. e1-192.e9.

21. Barbosa EC, Bomfim Ade S, Benchimol-Barbosa PR, Ginefra $P$ (2008) lonic mechanisms and vectorial model of early repolarization pattern in the surface electrocardiogram of the athlete. Ann Noninvasive Electrocardiol 13: 301-307.

22. Biasco L, Cristoforetti Y, Castagno D, Giustetto C, Astegiano $P$, et al. (2013) Clinical, electrocardiographic, echocardiographic characteristics and long-term follow-up of elite soccer players with J-point elevation. Circ Arrhythm Electrophysiol 6: 1178-1184.

23. Quattrini FM, Pelliccia A, Assorgi R, Dipaolo FM, Squeo $M R$, et al. (2014) Benign clinical significance of J-wave pattern (early repolarization) in highly trained athletes. Heart Rhythm 11: 1974-1982.

24. Takagi M, Aihara N, Takaki H, Taguchi A, Shimizu W, et al. (2000) Clinical characteristics of patients with spontaneous or inducible ventricular fibrillation without apparent heart disease presenting with $\mathrm{J}$ wave and ST segment elevation in inferior leads. J Cardiovasc Electrophysiol 11: 844-848.

25. Benito B, Guasch E, Rivard L, Nattel S (2010) Clinical and mechanistic issues in early repolarization of normal variants and lethal arrhythmia syndromes. J Am Coll Cardiol 56: 1177-1186.

26. Antzelevitch C, Yan GX (2010) J wave syndromes. Heart Rhythm 7: 549-558.

27. Gussak I, George S, Bojovic B, Vajdic B (2008) ECG phenomena of the early ventricular repolarization in the 21 century. Indian Pacing Electrophysiol J 8: 149-157.

28. Bronis K, Kappas K, Manolis AS (2012) Early repolarization: Not benign any more - The J-wave syndrome. Hospital Chronicles 7: 215-228.

29. Sethi KK, Sethi K, Chutani SK (2014) Early repolarisation and J wave syndromes. Indian Heart J 66: 443-452. 